\title{
Esclavitud y libertad en tiempos de guerra: Respuestas de los negros al sitio británico de La Habana (1762-63)
}

\author{
por \\ Elena Schneider ${ }^{1}$ \\ University of California, Berkeley
}

Este artículo evalúa la invasión y la ocupación británicas de La Habana (1762-1763), como un acontecimiento en la historia de la diáspora africana y la esclavitud racial en el mundo atlántico. Las personas de ascendencia africana componían la mitad de la población de La Habana en ese momento, y desempeñaron una función central en los sucesos de la invasión y la ocupación. Este artículo hace uso de fuentes de archivos históricos de los Estados Unidos, Gran Bretaña, Jamaica, Cuba y España para investigar cómo los hombres y mujeres de una diáspora africana interrelacionada respondieron a este conflicto imperial.

Palabras Clave: diáspora africana; Guerra de los Siete Años; Cuba; Jamaica; marronage.

Cómo CitAR ESTE ARTículo / Citation: Schneider, Elena, «Esclavitud y libertad en tiempos de guerra: Respuestas de los negros al sitio británico de La Habana (1762-63)», Revista de Indias, LXXIX/275 (Madrid, 2019): 143-163. https://doi.org/10.3989/revindias.2019.005.

La invasión y ocupación de La Habana por Gran Bretaña hacia el final de la Guerra de los Siete Años fue uno de los conflictos militares sostenidos de mayor dimensión en el Caribe entre las guerras de conquista españolas y la Revolución Haitiana. Durante seis semanas en el verano de 1762, una fuerza de 30 buques de guerra británicos, acompañados de más de 200 navíos de transporte y apoyo, que transportaban a más de 26.000 soldados y marineros y 2.400 africanos esclavizados, levantados en Gran Bretaña, la Antigua, San Cristóbal, Martinica, Jamaica, y Anglo Norteamérica sitiaron y ocuparon La Habana, en aquel entonces la base naval más grande y de

\footnotetext{
1 eschneider@berkeley.edu, ORCID iD: https://orcid.org/0000-0003-0055-1526.
} 
mayor importancia estratégica, además de la tercera ciudad más populosa del hemisferio ${ }^{2}$.

Se trataba de mucho más que un simple episodio de rivalidad entre imperios. El sitio y ocupación de La Habana también constituyó un acontecimiento en la historia de la Diáspora Africana y de la esclavitud racial en el mundo atlántico. Aproximadamente la mitad de la población de La Habana a mediados del siglo XVIII estaba compuesta de personas de ascendencia africana. En el curso de las seis semanas del sitio, la ciudad se volvió mayoritariamente negra, a la vez que muchos españoles y criollos pudieron escaparse hacia lugares resguardados, al mismo tiempo la gente de color fue llegando, o fueron enviados, desde otros sectores de la Isla para luchar en la defensa de la ciudad. La fuerza expedicionaria británica, a su vez, incluía a unos 500 soldados negros libres, procedentes de Jamaica; 100 africanos esclavos desde la Martinica; 500 desde La Antigua y San Cristóbal; y 1.845 desde Jamaica ${ }^{3}$. Puesto que las rutas del comercio esclavista con destino a Cuba en el siglo XVIII pasaban mayormente desde y a través de Jamaica, esto significa que durante la invasión de La Habana, hubo gente de ascendencia africana alineada de uno y otro lado del conflicto, individuos que posiblemente eran conocidos unos de otros, o parientes o hasta compañeros de travesía atlántica, traídos desde África en los mismos barcos negreros británicos ${ }^{4}$.

Las fuerzas británicas y españolas estaban compuestas de individuos cuyas variadas elecciones de alineación, auto preservación y oportunismo fueron más complicadas de lo que podría suponerse a partir de los simples rótulos de «británico» y «español». Durante el transcurso de la invasión y ocupación, las po-

2 Basado en gran medida en mi manuscrito del libro, The Occupation of Havana: War, Trade, and Slavery in the Eighteenth-century Atlantic World, Chapel Hill, Omohundro Institute of Early American History and Culture/University of North Carolina Press, 2018 [La ocupación de La Habana: Guerra, comercio y esclavitud en el mundo atlántico del siglo XVIII].

3 Lyttelton to the Lords Commissioner of Trade and Plantation, Spanish Town, Jamaica, 12 May 1762, The National Archive, Kew (TNA), CO, 137.32, ff. 114-116. Keppel to Pocock, 23 May 1762, Huntington Library, San Marino, California (HL), Pocock's Papers, citado por Syrett, 1970: 125. Albemarle to Egremont, The Namur off Cape St. Nicolas, 27 May 1762, TNA, CO, 117.1, ff. 69-72, citado por Syrett, 1970: 136. Copies and Extracts of Letters from Governor Lyttelton to Commodore Forrest, the Earl of Albemarle, Sir James Douglas, etc. concerning the corps of free negroes and 2000 slaves raised in Jamaica for the late expedition against the Havannah, TNA, CO 137.61, ff. 147-158.

4 Obtenidos o bien por contrabandistas, por residentes de Cuba con licencia especial, por la Real Compañía de Comercio de La Habana [Royal Havana Company] o bajo el asiento de la South Sea Company, la mayoría de los individuos esclavizados arribados al oeste de Cuba en el medio siglo previo a 1762 llegaron por vía Jamaica. Otros llegaron por las rutas del cimarronaje marítimo desde la costa norte de Jamaica a la costa sur de Cuba. 
blaciones de ascendencia africana nominalmente «españolas» y «británicas», además de las categorías de «libres» y «esclavizados», tendían a desdibujarse, borroneándose las líneas divisorias entre unas y otras. Numerosos individuos pasaron de un bando a otro en el marco de este enfrentamiento de imperios; otros optaron por sustraerse al conflicto, en algunos casos con miras a un eventual traslado permanente, emigración, mejora o fuga. Las categorías de «Imperio Español» e «Imperio Británico» sí eran significativas para los actores contemporáneos, pero a la vez eran porosas; se las veía ora como obstáculos, ora como oportunidades, y esto era así tanto en tiempos de guerra como en tiempos de paz.

Las fuentes lo demuestran: las reacciones de la gente de ascendencia africana frente a la campaña británica por parte fueron tan variadas como lo eran sus historias personales y sus posiciones en la sociedad colonial. Sus respuestas también ilustran lo entrelazadas que habían quedado las poblaciones afrodescendientes de Cuba y de Jamaica, a raíz del comercio esclavista antes del arribo de los buques de guerra británicos a las orillas cubanas. Además de los que se alistaron como voluntarios en los ejércitos de ambas Coronas, damos con afrodescendientes que se daban a la fuga ya fuera a pie o por barco, pasaban como desertores a las filas contrarias, se hacían pasar por «británicos» o por «españoles», se desempeñaban como espías, robaban, saqueaban, cometían violaciones y asesinaban a blancos, y continuaron luchando aun después de la rendición formal de La Habana.

Como lo escribió Olaudah Equiano, «Cuando esclavizas a los hombres, los obligas a vivir contigo en un estado de guerra $\aleph^{5}$. ¿Qué ocurrió, entonces, cuando dos sociedades que dependían de la mano de obra de gente de ascendencia africana, y estaban entrelazadas una con la otra por los circuitos del comercio esclavista, entraron en estado de guerra una contra la otra? ¿Cómo respondieron hombres y mujeres de una diáspora africana estrechamente conectada frente a este conflicto imperial y al traspaso de la soberanía? Como la narrativa de estos acontecimientos lo pondrá de manifiesto, estalló un cierto grado de conflicto violento entre gentes de ascendencia africana y de ascendencia europea, en el marco de la batalla entre Gran Bretaña y España. ¿Cuáles fueron las consecuencias, cuál fue el legado, de estos sucesos históricos en Cuba?

\section{EL ROL DE LA GENTE DE ASCENDENCIA AFRICANA EN EL SITIO}

Hay límites a lo que podremos alguna vez saber acerca de lo que ocurre en el combate, particularmente cuando éste se da entre los que están ubicados en

\footnotetext{
5 Equiano, 1995: 111.
} 
la parte inferior del orden social o racial, lejos de la producción de los documentos de archivo. Como siempre se da con la guerra, la polémica se inscribe inmediatamente en versiones encontradas de los acontecimientos. Viene al caso la cuestión del destino de mucho de los negros y mulatos en la fortaleza de El Morro, que defiende la entrada de la Bahía de La Habana, luego de que las fuerzas británicas recurrieran a la medida extrema de minar y destruirla el 30 de julio. Este episodio demuestra no solamente cuántos individuos de ascendencia africana prestaron servicio en primera línea de la resistencia al sitio, sino también cuán difícil es rastrear su experiencia, y con cuánta frecuencia ésta se ha borrado memoria de este capítulo de la historia.

Dos fuentes españolas de la época afirman que cuando los efectivos británicos asaltaron la fortaleza de El Morro al final del sitio, «acuchillaron» a muchos de los negros y mulatos armados que encontraron allí6. De acuerdo a las actas del concejo municipal, muchos negros en la plaza se fugaron poco tiempo después, «atemorizados de los insultos de los enemigos en la toma de la plaza $\gg$. En carta a un corresponsal en Madrid, escrita al poco tiempo de la rendición, un residente de La Habana interpretó esta despiadada conducta hacia negros españoles armados como un acto de venganza por los muchos ataques realizados por efectivos negros contra los combatientes británicos ${ }^{8}$.

Fuentes británicas corroboran que las tropas acuchillaron a cuchillo algunos soldados en el Morro, aunque no admiten que tenía que ver con la raza9 Los informes oficiales británicos no hacen ninguna mención específica de los negros defensores de El Morro, y los relatos de los testigos de primera mano no concuerdan entre sí acerca del número de tropas españolas muertas. Tanto un soldado como un oficial británico, en sus diarios, anotaron la «matanza en el acto» de 400 hombres, mientras el parte oficial de Keppel cuenta tan sólo 130 españoles muertos, 37 lesionados, 326 capturados y 213 ahogados al

6 Carta de Don Juan Miguel Palomino a Don Nicolas de Ribera, vecino de Madrid, fecha en la Havana a 28 de agosto de 1762 sobre la toma de aquella plaza por los ingleses, Biblioteca Nacional José Martí, La Habana (BNJM), C. M. Pérez. Also British Library, London (BL), Add. Mss. 13,976. Noticias de la Habana que refiere como ganaron los Ingleses el año de 1762, Biblioteca Nacional de España, Madrid (BNE), Ms. 10818/33.

7 Roig de Leuchsenring, 1962: 114, 119.

8 Carta de Don Juan Miguel Palomino, BNJM, C. M. Pérez, «La razon que tuvo el ingles de matar a los negros y mulatos del Morro, consistió en las correrias que estos le hicieron barbaramente, pues 20 se descolgaron del fuerte en una occasion, no más que con sus machetes, y a pesar de los fuziles se metieron en una trinchera, mataron a los que no huyeron, y huvieran clavado la artilleria varios honradissimamente, disminuyendo las fuerzas del enemigo a costas de sus vidas».

9 Cannon, 1847: 147. 
intentar fugarse o muertos por balazos en barcos. El parte de Keppel no se refiere a la raza de estos «españoles», ni tampoco lo hacen la mayoría de las posteriores historias del sitio, entre ellas todas las escritas por historiadores de lengua inglesa y por no cubanos ${ }^{10}$.

Si bien es difícil corroborarlo de modo definitivo a partir de las fuentes, la matanza de muchos de los negros y mulatos defensores de El Morro no hubiera sido del todo inesperado, en función de la lógica de los soldados y comandantes británicos. Sería comprensible como espasmo de violencia nutrida por una profunda desvalorización de las vidas negras y de todas las vidas, a medida que se prolongaban los combates, y en medio de tanta muerte y enfermedad, pero particularmente hacia las vidas negras. También delata una ansiedad particularmente británica ante la propia incapacidad de controlar a hombres negros militarizados. Las experiencias recientes durante las «Maroon Wars» y la Rebelión de Tacky en Jamaica habían puesto al descubierto las dificultades para dominar a africanos esclavizados. Los dueños de esclavos en Jamaica que arrendaban a su propiedad humana para prestar servicio en el sitio de La Habana expresaban su preferencia de que sus «aportes» fueran usados como mano de obra y no como «negros de combate», preferencia arraigada en el temor de que a su retorno a Jamaica quedaran inmanejables ${ }^{11}$. No puede ser casual que Albemarle haya decidido dejar atrás a tantos de los negros esclavos y libres que había traído consigo en la campaña de Cuba, en vez de devolvérselos a sus dueños originales en las Antillas inglesas, o dejarlos en los que habían sido sus lugares de embarque en Jamaica, La Antigua, San Cristóbal y Martinica.

Los hombres negros, tanto libres como esclavizados, posiblemente hayan estado además particularmente indispuestos a rendirse pacíficamente, y con mayor inclinación que sus pares blancos por luchar hasta la muerte. Sin duda

10 Commonplace book of John Sinclair, 1762-1801, Duke University, Perkins Library, Special Collections, Durham, North Carolina: 9. Henry Fletcher, Seven Years' War Journal of the Proceedings of the $35^{\text {th }}$ regiment of foot, by a British officer, and illustrated by a military engineer, August 1757-December 1765, John Carter Brown Library, Providence, Rhode Island (JCBL), Codex English 41, entrada correspondiente al 30 julio 1762. Placer Cervera, 2007: 170; 2003. Las excepciones incluyen Deschamps Chapeaux, 1976: 29. Dos historiadores cubanos del siglo XX relatan este asesinato de soldados negros y mulatos en El Morro en relatos editados, pero ningún otro historiador —ni británico, ni español, ni cubano, ni norteamericano - se ocupa siquiera del asunto. García del Pino, 2002: 123. Véase también Pérez de la Riva, 1962. Entre las historias escritas por historiadores británicos y norteamericanos que no hacen mención de este incidente: Hart, 1931. Syrett, 1970. Thomas, 1971.

11 House of Assembly Journals, 14 April 1762, Jamaican National Archive, Spanish Town (JNA). 
se sabían más allá de la plena protección de las reglas de la guerra, y en el caso de los libres particularmente vulnerables a quedar re-esclavizados una vez finalizada la guerra ${ }^{12}$. Los voluntarios esclavos, que luchaban a cambio de una prometida liberación, como asimismo los milicianos negros, posiblemente eran particularmente renuentes a bajar las armas y entregarse a la voluntad de sus adversarios británicos. Según lo señaló un español en su diario, la libertad de los africanos esclavizados que combatían en las filas de la Corona Española, se entendía que dependía del triunfo en la guerra, ya que esa libertad se la habían prometido el monarca español, y no su par británico contra quien libraban tan denodada lucha ${ }^{13}$. Hombres tan fuertemente motivados posiblemente hayan estado indispuestos a bajar las armas, o tal vez sus pares británicos los imaginaban inmanejables como prisioneros de guerra. Es muy probable que haya sido tanto la intensidad de su sed de libertad, como la de su amor patrio, que en este caso condujo a que sacrificaran todo.

Hombres de ascendencia africana combatieron de ambos lados de este conflicto imperial, pero desempeñaron un rol particularmente importante en la defensa de La Habana. Para el año 1762, los hombres libres de ascendencia africana ya eran herederos de una larga y honrosa historia de servicio a la Corona en las milicias de Cuba. Lo habían hecho no sólo en la defensa de su patria sino también en operaciones ofensivas en la Florida y Georgia, y a bordo de naves corsarias durante anteriores guerras del siglo XVIII. A diferencia de las autoridades británicas, que eran más principiantes en estos oficios, en Cuba las autoridades españolas llevaban desde el 1600 organizando a gente de color libre en compañías de soldados. Estos hombres se alistaban voluntariamente en las filas de las milicias a cambio del elevado estatus, los derechos y los privilegios asociados con el servicio militar ${ }^{14}$. Más de mil milicianos negros y mulatos, libres, entraron a la plaza a prestar servicio en el transcurso del sitio británico de La Habana ${ }^{15}$.

Además de estos milicianos, africanos esclavizados desempeñaron un rol clave en el conflicto. Temiendo que los británicos ofrecieran la libertad a todo africano esclavizado que se sublevara y se uniera a las fuerzas británicas, Juan de Prado, gobernador de La Habana decretó con fecha 9 de junio que aquellos

12 Sobre el monarquismo entre poblaciones de ascendencia africana, véase Thornton, 1993. Fick, 1990. Echeverrí, 2011.

13 Rodríguez, 1963: 25, «a los negros esclavos el Rey los pone francos a todos saliendo con victoria de esta función».

14 Klein, 1966. Deschamps Chapeaux, 1976. Landers, 2006; 2010.

15 Prado a Juan Ignacio de Madariaga, Madrid, 20 April 1762, Archivo General de Indias, Sevilla (AGI), Ultramar, 169. 
esclavos en Cuba que acudieran a La Habana y participaran de la defensa de la ciudad obtendrían a cambio de tal servicio su libertad. Joseph Antonio Moreno, un hombre esclavizado procedente de Puerto del Príncipe (hoy Camagüey), informó en un memorial que no bien anunciado el decreto en su ciudad, «corrió» (así la expresión de Moreno) el trayecto de 150 leguas para ir a presentarse a La Habana. En el recuento final ordenado por la Corona después de la pérdida de La Habana, declaró que fueron tantos los africanos esclavizados que llegaban a la ciudad durante los combates para prestar servicio a cambio de su libertad, que le era imposible «calcular» su número ${ }^{16}$.

De acuerdo al diario del sitio mantenido por Prado, a los más «capaces» de los esclavizados se los iba a destinar a ejercer las armas, mientras que los bozales, naturales de África, se los emplearía en actividades «más adaptables a su comprehensión» tales como tareas manuales ${ }^{17}$. En ambos casos, se suponía que se fomentaría el alistamiento de reclutas con la promesa de libertad si su desempeño resultara merecedor. Según un dueño de ingenio en Cuba, el gobernador Prado ordenó a los dueños de haciendas agrícolas permitir que la mitad de sus esclavos se trasladara a La Habana para unirse a la defensa de la ciudad. Se informó posteriormente que acudieron esclavos procedentes de más de 100 haciendas, presentándose como voluntarios ${ }^{18}$. El mismo dueño de ingenio, Don Carlos del Rey, declaró a principios de junio 1762 haber enviado a 25 de sus mejores esclavos, armados con machetes y también cargando azadas, para que los movilizaran para la defensa de las fortalezas de la Cabaña y de El Morro' ${ }^{19}$.

La distinción entre libres y esclavos, con respecto a la gente de ascendencia africana, tendía a desdibujarse en medio de las exigencias del sitio. Las fuentes de la época sugieren que algunos negros criollos esclavizados, esto es, gente de origen africano y nacimiento en Cuba pudieron insinuarse en las milicias presuntamente de negros libres; tal vez esto se debía a las conexiones que gozaban los negros criollos con la comunidad negra libre. Otros pasaron a integrar compañías improvisadas de voluntarios esclavos, en muchos casos

16 Carta de Joseph Antonio Moreno, AGI, SD, 2208. Juan Ignacio de Madariaga, Madrid, 20 Abril 1763, AGI, Ultramar, 169. Cabildo de la Habana, 26 August 1762, AGI, SD, 1356.

17 Diarios de las operaciones del sitio de la Habana en 1762 formados por el Governador de ella Don Juan de Prado y por el Gefe de Escuadra Marques del Real Transporte, en Proceso..., 1763, vol. I: 9.

18 El cabildo secular, La Habana, 26 agosto 1762, AGI, SD, 1356.

19 Servicios y exercicios literarios del Doctor Don Carlos del Rey, Presbytero, Domiciliario de la Haban, AGI, SD, 1357. Relación de los meritos y servicios de Don Joseph Cypriano de la Luz, Correo Mayor que ha sido de la isla de Cuba y regidor perpetuo por Su Majestad de la cuidad de San Cristobal de la Habana, AGI, Indiferente, 2821. 
con comandantes blancos, quienes llegaban a la plaza o fueron convocados allí durante el sitio, desde el interior de la Isla ${ }^{20}$. Gracias a sus éxitos en el campo de batalla, los africanos esclavizados vieron expandirse, a lo largo del sitio, su rol como soldados y no sólo auxiliares.

Desde fecha tan temprana como el 13 de junio, se anunciaba que no importaba cual fuere el color de piel o estatus legal de uno, el que lograra capturar a un soldado británico sería premiado por el Rey con 30 pesos fuertes. Diez pesos era el premio correspondiente a un marinero británico. Los negros se mostraron notablemente exitosos en este tipo de misión. Un hombre esclavizado de nombre Joseph Antonio Barreto, quien prestaba servicio en El Morro, relató haber sido enviado por el oficial comandante a que luchara contra los ingleses «cuerpo a cuerpo», sin arma. Según declaró, pudo «coger un prisionero por los cabellos»y hacerlo marchar hasta el oficial comandante ${ }^{21}$.

Fueron esclavos soldados los que obtuvieron uno de los pocos éxitos célebres en la defensa de La Habana. El 26 de junio, trece de ellos sorprendieron a un destacamento de vanguardia de soldados británicos que avanzaban hacia la fortaleza de El Morro. Blandiendo nada más que machetes contra las armas de fuego del enemigo, mataron a un soldado, tomaron a siete prisioneros y provocaron la fuga de los demás ${ }^{22}$. Como recompensa a su hazaña, el gobernador de La Habana otorgó a estos hombres, en su mayoría negros criollos, su libertad de modo inmediato, en plena guerra. Formó además otra compañía de 100 hombres esclavizados, con oficial comandante blanco, a fin de expandir su rol como milicianos participando de la defensa. A ellos también se los emancipó como premio a sus proezas en el transcurso de la batalla ${ }^{23}$.

Como lo sugiere este incidente, gente de ascendencia africana era altamente visible en la primera línea de la resistencia española al ataque británico. Figuran en los diarios de soldados británicos referencias a la preponderancia de negros y mulatos en la defensa de la fortaleza de El Morro. De acuerdo tanto a fuentes españolas como británicas, personas de ascendencia africana desempeñaron un rol prominente en las pocas operaciones ofensivas empren-

20 Prado a Juan Ignacio Madariaga, La Habana, 17 julio 1762, AGI, Ultramar, 169, «Han entrado 194 negros esclavos de la compañias de Trinidad, el Cayo, y Santi Spiritus, y hoy 164 entre negros y gente blanca de Arroyo de Arenas, que en todos se compone el número de 258 hombres».

21 Testimonio de los autos obrados sobre las livertades dadas a diferentes negros esclavos que sirvieron en el tiempo de la invasión de esta plaza, 1764, ff. 8v-9v, AGI, SD, 2209.

22 Julián de Arriaga al Conde de Ricla, Aranjuez, 13 mayo 1763, AGI, SD 1213. Placer Cervera, 2007: 153-4. García del Pino, 2002: 94.

23 AGI, SD, 2209. 
didas por los españoles contra el invasor ${ }^{24}$. El 22 de julio, mientras las fuerzas que defendían la ciudad lanzaban su contraataque más osado y sostenido, con la intención de desalojar a las fuerzas británicas de la fortaleza de la Cabaña, el combate duró aproximadamente una hora. Después los británicos permitieron que los españoles recuperaran a sus muertos. Según el diario de un soldado español, entre éstos se hallaban los restos de 61 soldados negros y guachinangos, a los que juntaron y enterraron en el cementerio del pueblo de Regla, en la orilla opuesta de la bahía, enfrente de la ciudad amurallada ${ }^{25}$.

Dada su creciente concentración en La Habana en los últimos y sangrientos días del sitio, la gente de color libre y esclavizada sufrió bajas fuera de toda proporción en relación con su población en la Isla. En un relato particularmente funesto de los días finales, Thomas Butler, jesuita de La Habana, escribió que una sola bomba que dio en la ciudad amurallada mató de un tirón a 15 negros. Más tarde, Prado estimó que por lo menos 900 esclavos murieron durante el sitio, aunque sus cifras no son fiables ${ }^{26}$.

¿Qué es lo que habría impulsado a estos voluntarios a estar tan dispuestos a arriesgar sus vidas? Muchos de ellos eran veteranos, combatientes experimentados en guerras anteriores del siglo XVIII. Si bien los nombres de muchas de estas personas de ascendencia africana que se destacaron en el campo de batalla nos señalan que eran negros criollos, también es probable que entre ellos se hayan contado algunos que eran veteranos no solamente de guerras americanas sino también africanas. Esto lo torna más probable el hecho de que tuvieran tal éxito en las razias y capturando al enemigo ${ }^{27}$. Dado el hecho de que, en muchos casos, luchaban por su libertad además que en defensa del Rey, es posible que los negros esclavizados hayan estado particularmente dispuestos a correr riesgos.

Además, en algunos casos había incentivos financieros directos en juego, mucho más grandes de lo que en tiempos de paz estuviera al alcance de la gente de ascendencia africana. Otros combatientes remarcaron sobre la destreza y la tremenda motivación de los hombres de ascendencia africana para tomar prisioneros. Un marinero español comentó en su diario del sitio que los negros realizaban «diabluras», por lo que puede entenderse hazañas tremen-

24 Robertson, 1970: 55-6. Diario de Don Juan de Casta, entrada de 22 julio 1762, New York Public Library (NYPL).

25 Diario de Don Juan de Casta, entrada de 22 julio 1762, NYPL. Véase también Trelles, 1925: 9. Los guachinangos son individuos sometidos a un régimen de mano de obra forzada, enviados desde la Nueva España y en muchos casos de origen indígena.

${ }^{26}$ Carta del Jesuita Thomas Butler, 12 diciembre 1763, f. 15, BNJM, C.M. Pérez n. ${ }^{\circ} 26$.

27 Thornton, 1999; 1991. 
damente osadas, emprendidas sin temor por la propia integridad física, como si estuvieran poseídos por el Demonio, a fin de capturar a ingleses y obtener este premio. Por cierto, esta apreciación está filtrada por la pantalla de las percepciones españolas hacia la gente de ascendencia africana; sin embargo, el comentario también sugiere la posible presencia de hombres con experiencia en la toma de cautivos en guerras africanas ${ }^{28}$.

\section{LA DESERCIÓN}

Los británicos trajeron aproximadamente 2,500 personas de ascendencia africana en la campaña de La Habana, las que fueron empleadas en las tareas físicas más exigentes, tales como el traslado de piezas de artillería y la construcción de baterías temporales. Este tipo de labor, se decía, debilitaba la resistencia física y hacía a los trabajadores más susceptibles a las enfermedades tropicales. Se los veía como más sacrificables o tal vez como más resistentes a las enfermedades, y se utilizaba de esta manera a los conscriptos esclavizados y negros libres para salvaguardar la salud de los soldados blancos ${ }^{29}$.

De acuerdo a los registros del comandante británico Lord Albemarle, a poco más del mes de iniciado el sitio, 25 de las tropas de color libres procedentes de Jamaica ya habían desertado de las filas británicas. ${ }^{30}$ Siendo tan sólo 500 hombres en un ejército de 12,000, las tropas negras libres de Jamaica constituían uno de cada cinco desertores de las fuerzas británicas a esta altura del sitio. Ya renuentes a alistarse en las filas militares, dejando atrás a sus familias y sus pequeños negocios en Jamaica, un porcentaje de estos hombres estimaban que había algo que ganar escapándose de los combates (o tal vez de la fiebre amarilla que hacía estragos entre las tropas) y adentrándose en Cuba.

Los oficiales británicos hacían uso frecuente de negros libres o esclavizados para obtener provisiones detrás de las líneas enemigas ${ }^{31}$. Estas tareas fueron asignadas a afrodescendientes probablemente por creerse que podrían hacerse pasar por «negros españoles» con más facilidad que un británico blanco tratando de hacerse pasar por español, a la vez realizando tan peligro-

28 Diario del manuscrito de Madrid, entradas del 13 y 29 junio 1762, en Rodríguez, 1963: 25, 29.

29 Syrett, 1970: 93. Albemarle a Pocock, 27 abril 1762, HL, Pocock's Papers, citado en Syrett, 1970: 100. TNA, CO 117.1, ff. 69-72, citado en Syrett, 1970: 137.

30 TNA, CO 117.1, ff. 81-82.

31 Bollettino, 2009: 124. William Howe a Pocock, Villa de San Antonio, 17 junio 1762, HL, Pocock Papers, PO 816. 
sa misión. Es importante notar que este tipo de tarea brindaba muchas oportunidades de fuga, ya sea al monte o a las líneas enemigas.

Hacerse pasar por libre en Cuba era más fácil, potencialmente, que en una colonia británica como Jamaica donde la proporción de individuos de ese estatus era mucho menor. De ser detenido por las autoridades, un desertor podía ofrecer información o manifestar el deseo de convertirse al catolicismo - o ambas cosas - a fin de reclamar la propia libertad. En la época, la política de la Corona Española de ofrecer la libertad a aquellos africanos esclavizados por los británicos que se fugaran a tierras españolas y manifestaran el deseo de convertirse al catolicismo, era notorio entre los afrodescendientes en Jamaica. Ya había habido una larga historia de cimarronaje marítimo desde la costa norte de Jamaica a la costa sur de Cuba.

Desertaron tantos africanos esclavizados y hombres de color libres de las filas británicas a lo largo de la invasión y ocupación, que al año de la devolución de La Habana a España, las autoridades locales todavía lidiaban con el problema de qué hacer con los relativamente numerosos «negros ingleses» que se habían fugado de sus unidades durante el sitio y ocupación, y que habían sido capturados o seguían prófugos ${ }^{32}$.

El 40\% de los esclavos procedentes de Jamaica nunca fueron devueltos a sus dueños. Los que sobrevivieron a la batalla se unieron de modo permanente a la población de ascendencia africana de Cuba. Además, Albemarle nunca devolvió a los 350 esclavos que aun podía identificar de entre los 500 que se había traído desde las Islas de Sotavento, sino que los vendió al sacerdote jesuita de La Habana, el Padre Thomas Butler; lo más probable es que hayan pasado el resto de sus vidas en $\mathrm{Cuba}^{33}$.

Este fue uno de los principales impactos de la invasión y ocupación de La Habana por Gran Bretaña, al considerar estos acontecimientos en el marco histórico de la Diáspora Africana. Atestiguó la incorporación a la población en Cuba de ascendencia africana de hasta 800 individuos procedentes de otras islas del Caribe. Entre estos individuos se contaban «negros ingleses» y «negros franceses», con habilidades lingüísticas, experiencia laboral y conocimientos culturales obtenidos en las Antillas Francesas e Inglesas. Este influjo de gente también significó un incremento exponencial del número de personas afrodescendientes en la Isla que contaban con experiencia militar.

32 Conde de Ricla a Julian de Arriaga, «sobre la libertad que el Rey ha concedido a los negros ingleses», La Habana, 3 julio 1764, AGI, SD, 1213.

33 Jamaica Sessional Papers, 13 febrero 1763, TNA, CO 140.42. López Mesa, 2000: 29-40. 


\section{LOS LÍMITES DEL DOMINIO}

Muchos desertores de ascendencia africana dejaban atrás a ambos bandos, aprovechando la oportunidad de darse a la fuga hacia las montañas. En los primeros días del sitio, particularmente, muchos negros que vivían en $\mathrm{La}$ Habana explotaron el ambiente caótico en la ciudad para huirse hacia el interior de la Isla. Durante toda la campaña británica, se oían quejas constantes acerca de bandas de esclavos fugitivos que robaban alimentos o realizaban razias contra los refugiados de la ciudad ${ }^{34}$. Una fuente se lamentaba de que las familias que huían de la ciudad se encontraban sitiados por igual por los ataques del enemigo y los de los negros quienes, estos últimos, en territorio abierto «no son menos feroces enemigos» ${ }^{35}$.

Se culpa a negros al igual que a blancos de violaciones durante las primeras, caóticas, semanas del sitio. En su diario, un español afirmó que el 22 de junio seis hombres, identificados como negros y blancos, habían sido detenidos por haber cometido no sólo robos y violaciones de mujeres, sino que salvajemente asesinaron y descuartizaron a sus víctimas femeninos ${ }^{36}$. Estas acusaciones no merecen necesariamente una fe literal, pero sí reflejan un verdadero peligro que amenazaba a las mujeres en particular y un ambiente que las autoridades percibían... Escribió en su diario: «Sin embargo del destrozo referido que han hecho los ingleses peor ha sido el que han executado los nuestros havaneros, así blancos como negros» ${ }^{37}$.

Entre aquellos miembros de la población de ascendencia africana en Cuba, había quienes contaban con experiencia anterior viviendo en colonias británicas, y que aprovechaban la oportunidad de pasar al bando británico y hasta de realizar espionaje. En cierta cantidad de casos, pasaron esclavos del lado español al británico para obtener su libertad, salir de la Isla y volver a sus lugares de origen. Hay tres casos de este tipo que figuran en el Archivo Nacional de Jamaica. Uno era un esclavo de Jamaica que había sido capturado por los españoles en la Bahía de Honduras y vendido a Cuba. Otros dos eran nacidos en Jamaica, pero posteriormente vendidos y trasladados a $\mathrm{Cuba}^{38}$.

${ }_{34}$ Diario de Don Juan de Casta, entrada del 27 julio, f. 16, NYPL.

35 Juan Miguel Palomino a Don Nicolas de Ribero, La Habana, 28 agosto 1762, BNJM, Colección Manuscritos Pérez. Otras copias: BL, Add. Mss. 13,976, ff. 298-299. Noticias de la Habana que refieren como la ganaron los ingleses, 29 August 1762, BNE, Ms. 10,818/33. «Ordenes, vandos, disposiciones, y otras providencias politicas y de buen govierno dadas por Don Juan de Prado, durante el sitio de la Habana», AGI, SD, 1584, n. 473.

36 Diario del Manuscrito de Madrid, en Rodríguez, 1963: 22, 27.

37 Ibidem: 27.

38 Manumission of Slaves, 1760-1765, f. 174v, JNA. 
Estos hombres podrían haber tenido bastante incentivo para volver a Jamaica donde tenían tal vez familia, o al menos un mayor dominio cultural y por lo tanto mejores posibilidades sociales y económicas.

Además de los casos de deserción, la correspondencia y los diarios del sitio aluden en muchas instancias a espías que pasaban información de un lado al otro. Estos individuos eran blancos, negros, de origen europeo o crio1lo; pero resulta interesante notar la presencia de gente de color entre sus filas. Debido a estos lazos entre las poblaciones de ascendencia africana en Cuba y en las colonias británicas, la gente de color estaba particularmente bien situada para poder explotar estas oportunidades de pasar de un bando al otro. Y no dudaron en hacerlo cuando les resultara conveniente.

Un ejemplo ocurrido en la primera etapa del sitio es el de un hombre esclavizado, originalmente de una colonia británica pero propiedad de un habitante de Guanabacoa, Cuba, que fue capturado vistiendo ropas británicas y usando dinero británico ${ }^{39}$. Al parecer, este individuo se había fugado, unido a las fuerzas británicas, y ahora realizaba tareas de reconocimiento u otras, detrás de las líneas españolas. De hecho, en medio del caos del sitio, los africanos esclavizados se hacían pasar por otra persona cuando era provechoso hacerlo. Este tipo de personas son poco propensas a aparecer en los registros históricos, pero veamos a continuación otro ejemplo. Un esclavo real español figura en los documentos como castigado por intentar hacerse pasar por desertor del lado británico, en un intento de beneficiarse de la política español de liberar a los esclavos fugitivos del enemigo ${ }^{40}$. Queda para la especulación el tipo de medidas a las que habría recurrido para representar el papel de «británico» a los ojos de los oficiales españoles, a fin de convencerles de que era procedente de una colonia británica y deseaba la conversión a la fe católica. Si sabía hablar inglés, habría sido la gran oportunidad para sacar a relucir esa destreza.

La apertura y las oportunidades disponibles a la explotación no deberían hacernos olvidar el tremendo peligro que traían las circunstancias. Esto era el caso no sólo para negros sino para blancos también. Sin embargo, dada su posición legal tan precaria en relación con los códigos de la guerra, el peligro era particularmente pronunciado para la gente de ascendencia africana.

39 Joseph Antonio Gomes a Prado, Ingenio La Barrera, 15 junio 1762, AGI, SD, 1585, n. ${ }^{\circ} 46$.

40 Lista de los presos que ya juzgados se remiten a la plaza para que hagan el servicio, San Juan, 18 julio 1762, AGI, SD, 1586, n. ${ }^{\circ}$ 176. Incluye a este hombre en una lista de presos y se refiere a él como "Sebastián Fuertes que se presentó como desertor agosar del indulto y ser de su Magestad». 
DESPUÉS DE LA RENDICIÓN

Un relato fiel de los acontecimientos del sitio enfocado en la gente de ascendencia africana no vería la rendición como el fin de la lucha. Tras la capitulación, muchos afrodescendientes, esclavizados y libres también, se dieron a la fuga, en una segunda oleada similar a la ocurrida en los comienzos de las hostilidades. Hubo versiones sobre un rumor que se difundió entre negros, esclavos y guachinangos en la plaza, de que los británicos los matarían por haber participado en la defensa de la plaza ${ }^{41}$. Esto fue poco tiempo después de la violencia en torno del minado, explosión y toma de El Morro.

Los acuerdos de capitulación dejaron en limbo a aquellos hombres esclavizados que habían luchado por su libertad en las filas españolas, ya que el soberano en cuyo nombre se les había prometido la libertad ya no ejercía la autoridad en el oeste de $\mathrm{Cuba}^{42}$. A diferencia de la toma de Martinica y de la Guadalupe por los británicos durante la Guerra de los Siete Años, la capitulación de La Habana no hizo mención alguna de los derechos ni del estatus de la gente de color libre en la Isla, ni tampoco de los esclavos allí a quienes se les había prometido la libertad a cambio de su servicio militar. En los artículos de capitulación de Martinica y la Guadalupe, que en otros particulares eran muy similares a los relacionados con La Habana, se liberaba a los individuos que habían defendido las islas a cambio de la promesa de liberación, si bien se los obligaba a abandonar la isla ${ }^{43}$. Otra disposición declaraba que ningún negro libre capturado por los británicos podría ser esclavizado. Sin embargo, en La Habana, no se dieron tales garantías; probablemente esto se debió a la ferocidad de los combates y al lugar destacado de los afrodescendientes en ellos.

Además, el cabildo de La Habana colaboró con las autoridades británicas al enviar a emisarios para capturar a los negros que se habían escapado al campo y devolverlos a los británicos a cambio de una recompensa, siendo el destino de los cautivos la venta en remate de esclavos ${ }^{44}$. En contraste con el cuidadoso acercamiento de Albemarle hacia los criollos blancos de La Habana, quienes llegaban en manada a la ciudad ocupada para aprovecharse de las oportunidades comerciales que ofrecía el control británico de la ciudad, Al-

${ }^{41} N^{\circ}{ }^{\circ}$ 6, 1765, AGI, SD, 1457.

42 Consejo de Indias $n .{ }^{\circ} 84,6$ septiembre 1768, AGI, SD, 1215. El Rey al Conde de Ricla, Madrid, 1 enero 1764, AGI, SD, 1212, f. 281. Artículo de capitulación $n .^{\circ} 14$, en Roig de Leuchsenring, 1962: 64.

43 Smelser, 1955: 139-142.

44 Ver por ejemplo la entrada de 19 de agosto en Roig de Leuchsenring, 1962: 73-75. 
bemarle no hizo tal esfuerzo para con la gente de color. Es más: reconociendo el «valor» de esa gente, puso incentivos para que los habaneros capturaran a negros y se los entregara para su posterior venta. Otros habitantes de Cuba se hicieron infames por merodear por el campo, motivados por el incentivo del pago ofrecido por los ocupadores británicos, apresando a negros libres para luego entregárselos a las autoridades británicas en La Habana. De hecho, dos hombres aparecen en las fuentes como dedicados al bandolerismo, no sólo apresando a negros libres sino también despojando de 200 pesos a una mujer afrodescendiente, quien denunció el asalto ${ }^{45}$.

En los siguientes meses de la ocupación, muchas personas de ascendencia africana resistieron la violencia con violencia, perturbando lo más posible lo que en otros aspectos era un dominio británico muy fácil de sostener. Aparte de los bandos de esclavos fugitivos que siguieron haciendo de las suyas en el campo, cierto número de negros hacían estragos dentro de los muros de $\mathrm{La}$ Habana, realizando robos y saqueos. Por lo menos cinco individuos afrodescendientes se vieron involucrados en asesinatos de súbditos británicos ${ }^{46}$. Después de la ocupación, un vecino de La Habana describió estos actos de resistencia como señales de «la lealtad no crehida» de los negros habaneros, pero también era posible interpretarlos como amenazas a todos los blancos en la ciudad $^{47}$.

Hemos hecho referencia al estado de limbo en que quedaron aquellos hombres esclavizados que habían luchado por su libertad en las filas españolas, tras la capitulación de la ciudad. Algunos de ellos se replegaron a partes de la Isla bajo control español, mientras que otros fueron apresados o se huyeron de la Isla, llegando algunos de ellos hasta España. El concejo municipal de Santa Clara, Cuba, informó que un mes después de la rendición, se albergaba a 320 veteranos de combate que se habían fugado tras la toma de la ciudad por los británicos; la mitad de ese número está identificada en los documentos como negros ${ }^{48}$. También hubo informes de bandas, en muchos casos de negros (fugitivos de La Habana o milicianos que habían luchado allí y que hicieron retirada en vez de rendirse), que robaban ganados de haciendas

45 Roig de Leuchsenring, 1962: 137.

46 Starr Meyers, 1909: 116. Joseph de Leon, AGI, SD, 1356. "Murder of two Philadelphia merchants, names of Read and Boyd”, Philadelphia Gazette, 26 mayo 1763. ANC, Miscelánea de Libros, n. ${ }^{\circ}$ 1435, en Franco, 1980: 46.

47 Carta anónima, La Habana, otoño 1763, Archivo General de Simancas (AGS), Hacienda, 2342.

48 Acta de cabildo de la villa de Santa Clara para organizar la defensa de la invasión inglesa en el año de 1762, BNJM, C.M. Pérez. 
que suministraban alimentos a La Habana, a fin de trastornar el aprovisionamiento de la ciudad ocupada por los británicos ${ }^{49}$.

\section{LEGADOS Y CONCLUSIÓN}

Para la gente de ascendencia africana de uno y otro lado del conflicto, el sitio supuso tremendo riesgo de muerte a la vez que el peligro de caer en la esclavitud, pero a la vez posibilitó una movilidad física y oportunidades para mejorar la condición de uno que muchos individuos tenían gran deseo de aprovechar. Los súbditos de España en Cuba consideraban a los afrodescendientes como extraordinariamente leales pero, según hemos visto, la realidad era considerablemente más compleja ${ }^{50}$. Las elecciones hechas por cada individuo reflejaban una compleja confluencia de historias personales, cálculos de riesgos y premios, la lealtad hacia un rey lejano, obediencia y desafío frente a las autoridades locales, el temor al invasor británico y las pasiones del momento.

Uno también puede ver en los acontecimientos de 1762 un contraste entre españoles y británicos en cuanto a la manera en que trataban a la gente de color durante las batallas y a estos veteranos después del conflicto. Al fin de la ocupación de La Habana, los comandantes británicos no querían tener que preocuparse más por muchos de los afrodescendientes libres y esclavizados a quienes habían traído en su campaña. Probablemente esto era el resultado de los éxitos logrados por los negros en la primera línea de resistencia al ataque británico, los fracasos de los esfuerzos británicos por lograr el control durante la ocupación, y las ganancias a obtener mediante su venta en La Habana. Los oficiales españoles, en cambio, se sintieron más afianzados por la experiencia vivida en La Habana. No bien volvieron a tomar posesión de la ciudad, una vez finalizada la guerra, y a lo largo de las décadas subsiguientes, el personal militar y gobernante expandió el empleo en Cuba y en otras zonas de la América Española de milicias de negros libres, mulatos y hasta de africanos esclavizados. También continuaron la tradición de enviarlos al extranjero durante la Guerra de Independencia Norteamericana ${ }^{51}$.

Esta confianza en los beneficios de armar a los negros en Cuba no duraría para siempre. Uno de los milicianos negros libres que lucharon en la Batalla

49 Roig de Leuchsenring, 1962: 191-199, 198-199.

50 Pedro Azerace al Rey, La Habana, 28 agosto 1762, AGI, Ultramar, 169, «el fervor y lealtad sin exemplo que respiran y han manifestado hasta los más humildes negros».

51 Landers, 2010: 142-143. 
de las Bahamas durante la Guerra de Independencia Norteamericana fue José Antonio Aponte. La rebelión que se asocia con su nombre ocurrió en 1812, cincuenta años después de la invasión y ocupación británica de La Habana, y fue el primer desafío importante a la esclavitud y a la soberanía española en $\mathrm{Cuba}^{52}$. Ese episodio ofrece al presente artículo un epílogo sugestivo.

En el juicio de Aponte, una prueba clave presentada en su contra fue un llamado «libro de pinturas» encontrado en su casa y que presuntamente él usaba para reclutar a otros negros a las filas de una rebelión coordinada que se fue extendiendo por la Isla. Entre las figuras representadas en sus páginas se contaban la imagen de un soldado negro reuniéndose con el Rey de España, quien le rendía homenaje y una representación de soldados negros victoriosos en combate contra tropas británicas. Cuando se le pidió durante el juicio que explicara esta última imagen, Aponte describió a su abuelo, junto a una compañía de soldados negros, tomando prisioneros británicos en $\mathrm{La}$ Habana. Lo corroboran los registros militares de España: el abuelo de Aponte luchó en la defensa de la ciudad en 1762 y fue aclamado por su actuación en dos enfrentamientos separados ${ }^{53}$. Tras la rendición de La Habana, varios veteranos negros del sitio se presentaron ante el Rey de España, Carlos III, y fueron condecorados por el monarca en reconocimiento de su servicio. Aponte habló de uno de esos veteranos durante su testimonio ${ }^{54}$.

Al evocar la memoria del servicio prestado por sus antepasados, Aponte argumentaba a favor de su propio abolengo como líder, a la vez que asociaba a su linaje con los líderes de Haití y con un monarca español benevolente. Para Aponte, el sitio británico de La Habana probablemente haya formado parte de una genealogía militar negra en Cuba y servido de modelo de la victoria de la gente afrodescendiente sobre ejércitos europeos. Aquellas imágenes también recuperaban, de algún modo, un pasado perdido, anterior al boom azucarero cubano y el endurecimiento de la esclavitud como institución y del pensamiento racial en la Isla, una época en que los milicianos de color en Cuba fueron otorgados audiencias en la corte real metropolitano y ceremonias de reconocimiento en la Plaza de Armas de La Habana, antes

52 Childs, 2006, especialmente capítulo 3. Landers, 2010: 158. Franco, 1963; 1977: 133 134. Ferrer, 2014: 271-329.

53 Expediente sobre declarar José Antonio Aponte el sentido que se hayan en el lugar que se le aprehendió en su casa, 24 marzo 1812, f. 37v, ANC, Asuntos Políticos, legajo 12, n. ${ }^{\circ}$ 17. AGI, Cuba, 1136A.

54 Expediente sobre declarar José Antonio Aponte el sentido que se hayan en el lugar que se le aprehendió en su casa, f. 36v, ANC, Asuntos Políticos, legajo 12, n. ${ }^{\circ}$ 17. Franco, 1963; 1977: 133-134. Childs, 2006: 25, 80-85. Fischer, 2004: 41-56. Palmié, 2002. Ferrer, 2014, capítulo 7. 
de que las cambiantes condiciones en la Isla se les volvieran crecientemente traicioneras ${ }^{55}$.

La imagen de Aponte subraya las contradicciones que se pusieron de manifiesto durante la invasión y ocupación, en el sentido de que la población de ascendencia africana demostró gran lealtad a la Corona Española a la vez que tremenda destreza derrotando, atacando, capturando y asesinando a blancos en La Habana. Además, el libro de pinturas de Aponte nos dice lo siguiente: en 1812, la memoria de la actuación que tuvieron los hombres de ascendencia africana en el sitio de La Habana seguía muy viva. Esto fue así a pesar de que el protagonismo de los antepasados de Aponte y de sus compañeros de combate, del que quedaron huellas innegables en los documentos de la época, ya comenzaban a borrarse de la historia oficial de aquellos hechos trascendentes en la historia cubana y mundial.

\section{BIBLIOGRAFÍA}

Anderson, Fred, Crucible of War: The Seven Years' War and the Fate of Empire in British North America, 1754-1766, New York, Vintage, 2000.

Bollettino, Maria Alessandra, Slavery, War, and Britain's Atlantic Empire: Black Soldiers, Sailors, and Rebels during the Seven Years' War, tesis doctoral no editada, Universidad de Texas, Austin, 2009.

Canon, Richard, Historical Record of the First or Royal Regiment of Foot, Containing an Account of the Regiment in the Reign of King James VI of Scotland and of Its Subsequent Services to 1846, London, Parker, Furnival \& Parker, 1847.

Childs, Matt, The 1812 Aponte Rebellion in Cuba and the Struggle Against Atlantic Slavery, Chapel Hill, NC, University of North Carolina Press, 2006.

Deschamps Chapeaux, Pedro, Los batallones de pardos y morenos libres, La Habana, Editorial Arte y Literatura, 1976.

Dubois, Laurent, Avengers of the New World: The Story of the Haitian Revolution, Cambridge, MA, Belknap Press Harvard University, 2004.

Echeverrí, Marcela, «Popular Royalists, Empire, and Politics in Southwestern New Granada, 1809-1819», Hispanic American Historical Review, 91/2 (Durham, NC, 2011): 248-255.

Equiano, Olaudah, The Interesting Narrative and Other Writings, editado por Vincent Carretta, New York, Penguin, 1995. Reimpreso en 2003.

55 Childs, 2006: 9. Landers, 2010: 158. 
Ferrer, Ada, Freedom's Mirror: Cuba and Haiti in the Age of Revolution, New York, Cambridge University Press, 2014.

Fick, Carolyn, The Making of Haiti: The Saint Domingue Revolution from Below, Knoxville, University of Tennessee Press, 1990.

Fischer, Sybille, «The Deadly Hermeneutics of the Trial of José Antonio Aponte», Modernity Disavowed: Haiti and the Cultures of Slavery in the Age of Revolution, Durham, NC, Duke University Press, 2004: 41-56.

Franco, José Luciano, La conspiración de Aponte, La Habana, Consejo Nacional de Cultura, 1963.

Franco, José Luciano, Las conspiraciones de 1810 y 1812, La Habana, Editorial de Ciencias Sociales, 1977.

Franco, José Luciano, Comercio clandestino de esclavos, La Habana, 1980. Reimpresión en 1996.

García del Pino, César, Toma de la Habana por los ingleses y sus antecedentes, La Habana, Editorial de Ciencias Sociales, 2002.

García Rodríguez, Mercedes, Los ingleses en el tráfico e introducción de esclavos en Cuba, 1715-1739, La Habana, Editorial de Ciencias Sociales, 2006.

Graham, Reverend John, Extracts from the Journal of the Reverend John Graham, Chaplain of the First Connecticut Regiment..., New York, Society of Colonial Wars, 1896.

Hart, Francis Russell, The Siege of Havana, 1762, New York y Boston, Houghton Mifflin, 1931.

Klein, Herbert S., «The Colored Militia of Cuba: 1568-1868», Caribbean Studies, 6/2 (Río Piedras, PR, julio 1966): 17-27.

Landers, Jane G., «Transforming Bondsmen Into Vassals: Arming Slaves in Colonial Spanish America», Philip D. Morgan and Christopher Leslie Brown (eds.), Arming Slaves: From Classical Times to the Modern Age, New Haven, CT, Yale University Press, 2006: 120-145.

Landers, Jane G., Atlantic Creoles in the Age of Revolutions, Cambridge, MA, Harvard University Press, 2010.

López Mesa, Enrique, «Acerca de la introducción de esclavos en La Habana durante la ocupación británica (1762-1763)», Rábida, 19 (Huelva, 2000): 29-40.

López Mesa, Enrique, «La trata negrera en el puerto de la Havana a mediados del siglo XVIII», Catauro: Revista cubana de antropología, 2/3 (La Habana, enero-junio 2001): 148-158.

McNeill, John Robert, Mosquito Empires: Ecology and War in the Greater Caribbean, 1620-1914, New York, Cambridge University Press, 2010. 
O’Malley, Gregory E., Final Passages: The Intercolonial Slave Trade of British America, 1619-180, Chapel Hill, NC, Omohundro Institute of Early American History \& Culture/University of North Carolina Press, 2014.

Palmié, Stephan, «'For Reasons of History”: José Antonio Aponte and His Libro de Pinturas», Wizards and Scientists: Explorations in Afro-Cuban Modernity and Tradition, Durham, NC, Duke University Press, 2002: 79-158.

Park, Roswell, «A Journal of the Expedition Against Cuba», University of Buffalo Studies, 1/4 (Buffalo, diciembre 1920): 231-243.

Pérez de la Riva, Juan, «Introducción», Grabados de Dominique Serres sobre la Toma de la Habana de 1762, La Habana, Biblioteca Nacional José Martí, 1962.

Placer Cervera, Gustavo, Los defensores del Morro, La Habana, Ediciones Union, 2003.

Placer Cervera, Gustavo, Inglaterra y La Habana: 1762, La Habana, Editorial de Ciencias Sociales, 2007.

Portuondo Zuñíga, Olga, Una derrota británica en Cuba, Santiago de Cuba, Editorial Oriente, 2000.

Proceso formado por orden del Rey Nuestro Señor por la Junta de Generales que S.M. se ha dignado de nombrar a este fin sobre la conducta que tuvieron en la defensa, capitulación, pérdida, y rendición de la plaza de la Habana, y esquadra, que se hallaba en su puerto el Mariscal de Campo Juan de Prado..., Madrid, Juan de San Martin, 1763-1764, 2 vols.

Putnam, Israel, The Two Putnams: Israel and Rufus in the Havana Expedition 1762 and in the Mississippi River Exploration. 1772-3, With Some Account of the Company of Military Adventurers, Hartford, Connecticut Historical Society, 1931.

Robertson, Archibald, Archibald Robertson: His Diaries and Sketches in America, 1762-1780, New York, New York Public Library/New York Times/Arno Press, 1970, reimpresión.

Rodríguez, Amalia A. (ed.), Cinco diarios del sitio de La Habana, La Havana, Biblioteca Nacional José Martí, 1963.

Roig de Leuchsenring, Emilio (ed.), La dominación inglesa de La Habana: Libro de cabildos, 1762-1763, La Habana, Oficina del historiador de la ciudad, 1962.

Smelser, Marshall, The Campaign for the Sugar Islands: A Study in Amphibious Warfare, Chapel Hill, NC, University of North Carolina Press, 1955.

Starr Meyers, William, «Journal of William Starr of Connecticut Regiment at Havana, 1762», Journal of American History, 4 (New York, 1909): 113-117.

Syrett, David (ed.), The Siege and Capture of Havana 1762, Great Britain, Navy Records Society, 1970.

Thomas, Hugh, Cuba or the Pursuit of Freedom, New York, Harper \& Row, 1977. 
Thornton, John, «African Soldiers in the Haitian Revolution», The Journal of Caribbean History, 25 (Kingston, 1991): 58-80.

Thornton, John, "'I am the Subject of the King of the Kongo': African Political Ideology and the Haitian Revolution», Journal of World History, 4/2 (Honolulu, HI, otoño 1993): 181-214.

Thornton, John, Warfare in Atlantic Africa, 1500-1800, London, University College London Press, 1999.

Trelles, Carlos M., El sitio de la Habana y la dominación británica en Cuba, La Habana, El Siglo XX, 1925.

Fecha de recepción: 20 de septiembre de 2016.

Fecha de aceptación: 10 de noviembre de 2016.

\section{Slavery and freedom in times of war: The black response to the British Siege of Havana (1762-63)}

This article evaluates the British siege and occupation of Havana (1762-1763) as an event in the history of the African diaspora and racial slavery in the Atlantic world. People of African descent made up half the population of Cuba at this time, and played a central role in the events of the invasion and occupation. This paper draws upon archival sources in the U.S., Britain, Jamaica, Cuba, and Spain to investigate how the men and women of an interconnected African diaspora responded to this imperial conflict.

KeY words: African diaspora; Seven Years' War; Cuba; Jamaica; marronage. 